\begin{tabular}{|c|c|}
\hline Title & Thickness dependence of proton conductivity of amorphous al uminosilicate nanofilm \\
\hline Author(s) & A oki, Y oshitaka; Habazaki, H.; Kunitake, Toyoki \\
\hline Citation & $\begin{array}{l}\text { Electrochemical and Solid-State Letters, 11(11), P13-P16 } \\
\text { https://doi.org/10.1149/1.2976305 }\end{array}$ \\
\hline Issue Date & 2008 \\
\hline DOC URL & http:/hdl.handle.net $/ 2115 / 35000$ \\
\hline Rights & $\begin{array}{l}\text { ๑) The Electrochemical Society, Inc. 2008. All rights reserved. Except as provided under U.S. copyright law, this work } \\
\text { may not be reproduced, resold, distributed, or modified without the express permission of The Electrochemical Society } \\
\text { (ECS). The archival version of this work was published in Electrochem. Solid-State Lett., V olume 11, Issue 11, pp. } \\
\text { P13P16 (2008). }\end{array}$ \\
\hline Type & article \\
\hline File Information & ESL 000P13.pdf \\
\hline
\end{tabular}

Instructions for use 


\title{
Thickness Dependence of Proton Conductivity of Amorphous Aluminosilicate Nanofilm
}

\author{
Yoshitaka Aoki, ${ }^{\text {a,z }}$ H. Habazaki, ${ }^{\text {a,* }}$ and Toyoki Kunitake ${ }^{\text {b }}$ \\ ${ }^{a}$ Graduate School of Engineering, Hokkaido University, Sapporo 060-8628, Japan \\ ${ }^{b}$ NanoMembrane Technologies, Incorporated, Wako 3510104, Japan
}

\begin{abstract}
$\mathrm{Al}_{x} \mathrm{Si}_{1-x} \mathrm{O}_{n}$ films exhibit a drastic change of proton conductivity across the film by reducing their thickness to less than $100 \mathrm{~nm}$. The temperature and humidity dependence of conductivity of the sub-100 nm films is quite different from those of the thicker films. Furthermore, in the former thickness range, the value of conductivity markedly increases with reducing the film thickness, and its thickness dependence follows a power law with a fixed index of -2.1 . This size-scaling effect can be explained by the percolation conductivity model that the probability for percolating of the conductive moiety in $\mathrm{Al}_{x} \mathrm{Si}_{1-x} \mathrm{O}_{n}$ films increases with decreasing the thickness.

(C) 2008 The Electrochemical Society. [DOI: 10.1149/1.2976305] All rights reserved.
\end{abstract}

Manuscript submitted June 12, 2008; revised manuscript received August 4, 2008. Published September 4, 2008.

Proton- and oxide ion-conducting metal oxides have attracted much attention as electrolyte material for solid oxide fuel cells. In particular, nanometer-thick membranes of these oxides are promising for developing next-generation intermediate-temperature fuel cells thanks to diminished area specific resistance (ASR) enabled by reduction in electrolyte thickness. ${ }^{1-3}$ Amorphous metal oxides have intrinsic advantages for their application to thin-film electrolyte due to their nongranular covalent networks. Recently, we discovered that silica-based, nanometer-thick films gave high proton conductivity at $100-400^{\circ} \mathrm{C}$ under nonhumidified atmosphere due to formation of stable Brønsted acid sites when doped with some other metal ions. ${ }^{4,5}$ Especially, the aluminosilicate, $\mathrm{Al}_{x} \mathrm{Si}_{1-x} \mathrm{O}_{n}$, nanofilm showed the highest proton conductivity and revealed practically usable levels of ASR at around $300^{\circ} \mathrm{C} .{ }^{5}$ Several other research groups reported that the ion conductivity of multilayered materials increased with decreasing layer thickness. ${ }^{6,7}$ These studies prompted us to study the effect of thickness for our $\mathrm{Al}_{x} \mathrm{Si}_{1-x} \mathrm{O}_{n}$ film. In fact, it is found that the proton conductivity of amorphous $\mathrm{Al}_{x} \mathrm{Si}_{1-x} \mathrm{O}_{n}$ films is exponentially enhanced by reduction of thickness into the sub- $100 \mathrm{~nm}$ regime.

The $\mathrm{Al}_{x} \mathrm{Si}_{1-x} \mathrm{O}_{n}$ film was prepared on an indium-tin-oxide (ITO) substrate (Aldrich) by multiple spin-coating of precursor solutions of tetraethoxysilane (TEOS) (Kanto) and aluminum sec-butoxide $\left[\mathrm{Al}\left(\mathrm{O}^{s} \mathrm{Bu}\right)_{3}\right]$ (Kanto) at the $\mathrm{Al} / \mathrm{Si}$ atomic ratio of $5 / 95$. The details of the procedure were described elsewhere. ${ }^{6}$ The metal concentration $(\mathrm{Al}+\mathrm{Si})$ in the precursor mixture sol was adjusted in $30 \mathrm{mM}$ for the film of $<100 \mathrm{~nm}$ thickness and $100 \mathrm{mM}$ for the film of $>100 \mathrm{~nm}$ thickness. A film with thickness of $100 \mathrm{~nm}$ was prepared from both of these sols. The precursor sols were spin-coated onto the ITO substrate at $3000 \mathrm{rpm}$ for $40 \mathrm{~s}$ by a Mikasa 1H-D7 spin coater. The deposited gel layer was hydrolyzed by blowing hot air for $30 \mathrm{~s}$ (Iuchi hot gun), and the substrate was cooled to room temperature by blowing cold air for $20 \mathrm{~s}$. These cycles of spin-coating, hydrolysis, and cooling were repeated 10-20 times, and the gel film thus obtained was calcined at $400^{\circ} \mathrm{C}$ for $15 \mathrm{~min}$. The combination of deposition and calcination was repeated more than three times, and the final calcination was performed at $450^{\circ} \mathrm{C}$ for $1 \mathrm{~h}$.

The thicknesses of the amorphous $\mathrm{Al}_{x} \mathrm{Si}_{1-x} \mathrm{O}_{n}$ films prepared in this study were 40, 50, 60, 100, 120, 160, 300, and $1400 \mathrm{~nm}$. Figure 1 shows the surface and cross-sectional scanning electron microscopy (SEM) images of the $50 \mathrm{~nm}$ thick film as an example, indicating that a dense, uniform layer with a thickness precision of $\pm 2 \mathrm{~nm}$ covers the ITO surface without formation of cracks and pores. All the films exhibited similar morphological features. These films are composed commonly of homogeneously mixed glasses without phase separation, as checked by transmission electron microscopy

\footnotetext{
* Electrochemical Society Active Member.

${ }^{\text {z }}$ E-mail: y-aoki@eng.hokudai.ac.jp
}

observation. ${ }^{4,5} \mathrm{Al} / \mathrm{Si}$ atomic ratio of the film was determined by X-ray photoelectron spectroscopy (XPS). Before XPS measurement, the surface layer (a few tens of nanometers thick) of sample was sputtered by $\mathrm{Ar}^{+}$ion so as to form a clean surface and probe the inner area of the films. The $\mathrm{Al} / \mathrm{Si}$ ratio in films is $10 / 90$ with a deviation of \pm 2 at all the thickness ranges, and the observed $\mathrm{Al} / \mathrm{Si}$ ratio is invariably greater than those of the corresponding precursor sol $(\mathrm{Al} / \mathrm{Si}=9 / 95)$. This must be caused by greater reactivity of $\mathrm{Al}\left(\mathrm{O}^{s} \mathrm{Bu}\right)_{3}$ than that of TEOS, and the unreacted fraction of TEOS (boiling point ca. $170^{\circ} \mathrm{C}$ ) may be removed from the ultrathin deposited layer by evaporation during the hot-air blow process after spincoating.

The proton conductivity across the film $(\sigma)$ was determined by ac impedance spectroscopy with a Solartron 1260 frequency analyzer. A Pt button electrode $(1 \mathrm{~mm} \phi)$ was deposited on the film by ion sputtering to form a Pt/ $\mathrm{Al}_{n} \mathrm{Si}_{1-n} \mathrm{O}_{x} / \mathrm{ITO}$ stack. For the measurement, nonhumidified "dry" atmosphere was prepared by flowing an ultrapure air $\left(\mathrm{N}_{2} / \mathrm{O}_{2}=8 / 2\right)$ at $100 \mathrm{~cm}^{3} \mathrm{~min}^{-1}$, and humidified "wet" atmosphere was prepared by bubbling an ultrapure air $\left(\mathrm{N}_{2} / \mathrm{O}_{2}\right.$ $=8 / 2)$ at $100 \mathrm{~cm}^{3} \mathrm{~min}^{-1}$ through pure $\mathrm{H}_{2} \mathrm{O}$ at $25^{\circ} \mathrm{C}\left(p_{\mathrm{H}_{2} \mathrm{O}}\right.$ $=0.023 \mathrm{~atm})$. All the films exhibit the impedance spectra characteristic of ion conducting film, that is, a small semicircle in the highfrequency region and a spike in the low-frequency region in the cole-cole plots (Fig. 2). These features are in agreement with those of the ion-conducting ceramics measured with ion-blocking electrode. ${ }^{8}$ The obtained impedance spectra were analyzed by the nonlinear least-squares fitting with an equivalent circuit displayed in Fig. 2.

The $\sigma$ value of $40 \mathrm{~nm}$ thick $\mathrm{Al}_{x} \mathrm{Si}_{1-x} \mathrm{O}_{n}$ films in dry air is shown in Fig. 3a. The film sample was first heated to $400^{\circ} \mathrm{C}$, kept for $6 \mathrm{~h}$, and cooled to given temperatures of impedance measurement, then heated to the subsequent temperature of measurement. All the measurements were performed after $1 \mathrm{~h}$ of thermal equilibration at each temperature. The $\sigma$ value in the first cooling process was reproduced in the second heating procedure, and the conductivity in the first cooling process was used thereafter. The conductivity of the $100 \mathrm{~nm}$ thick film prepared from the low-concentration sol is identical with
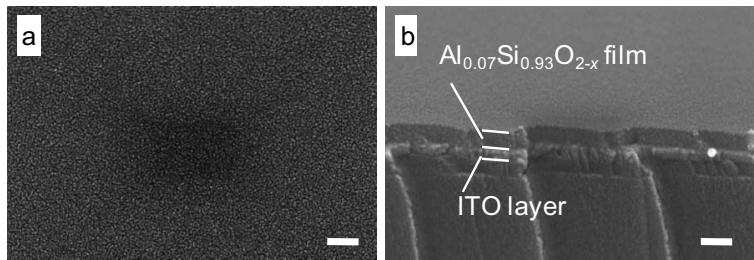

Figure 1. (a) Surface and (b) cross-sectional SEM images of a $50 \mathrm{~nm}$ thick $\mathrm{Al}_{x} \mathrm{Si}_{1-x} \mathrm{O}_{n}$ film. Scale bar is $100 \mathrm{~nm}$. 


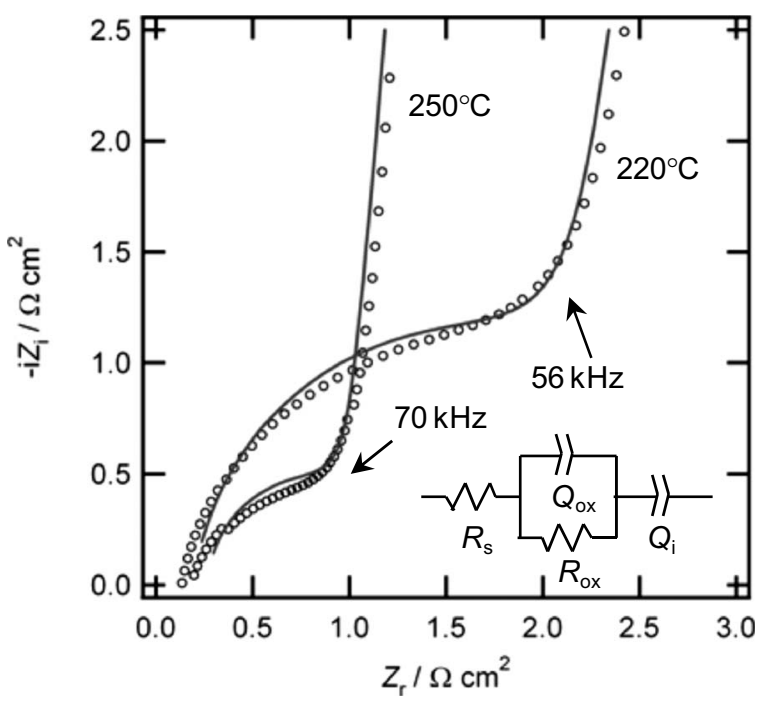

Figure 2. Cole-Cole plots of the impedance spectra of a $50 \mathrm{~nm}$ thick $\mathrm{Al}_{x} \mathrm{Si}_{1-x} \mathrm{O}_{n}$ nanofilm at 220 and $250^{\circ} \mathrm{C}:(\bigcirc)$ measured and $(-)$ calculated. The inset shows the equivalent circuit used for the nonlinear least-squares fitting analysis. $R_{\mathrm{s}}$ is the resistance of leads and electrodes, $R_{\mathrm{ox}}$ and $Q_{\mathrm{ox}}$ are the resistance and capacitance of the film, respectively, and $Q_{\mathrm{i}}$ is a capacitance at the interface between the ion-conductive film and the ion-blocking electrode.

that of the film prepared from the high-concentration sol (Fig. 3a), indicating that the film conductivity is not affected by the concentration of precursor sols.

Figure $3 \mathrm{~b}$ shows the proton conductivity of the films with thicknesses of 60 and $120 \mathrm{~nm}$ as measured in dry and wet air. Clearly, $\sigma$ of the $60 \mathrm{~nm}$ thick film does not change between dry and wet atmospheres. In contrast, $\sigma$ of the $120 \mathrm{~nm}$ thick film is clearly enhanced by humidity in the temperature region below $220^{\circ} \mathrm{C}$, but it remains unchanged by humidity above $250^{\circ} \mathrm{C}$. The $E_{\mathrm{a}}$ value of $\sigma$ in wet air, determined from the slope, is $0.3 \mathrm{eV}$ at $T<250^{\circ} \mathrm{C}$ and $0.8 \mathrm{eV}$ at $T>250^{\circ} \mathrm{C}$. Apparently, the relatively high proton conductivity at elevated temperatures $\left(T>300^{\circ} \mathrm{C}\right)$ is not affected by the adsorbed

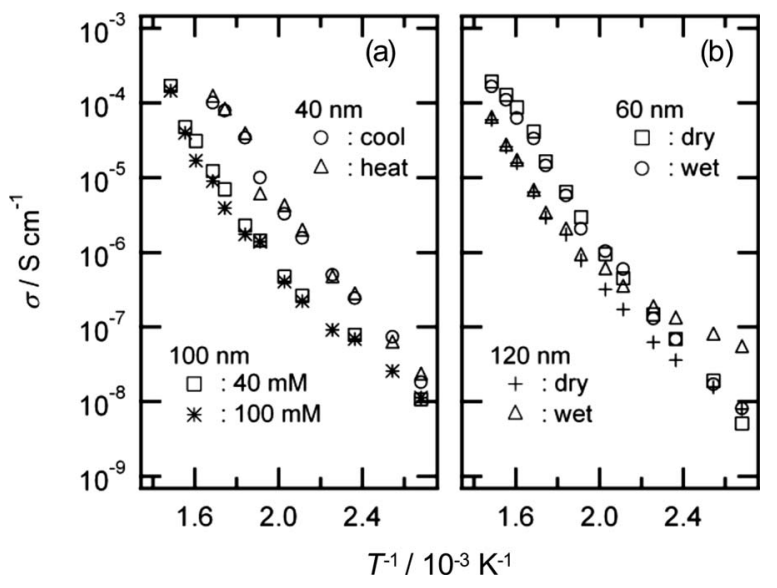

Figure 3. (a) Conductivity of a $40 \mathrm{~nm}$ thick film measured in $(O)$ the first cooling cycle and $(\triangle)$ the second heating cycle, and conductivity of $100 \mathrm{~nm}$ thick film prepared from the precursor sol of $40 \mathrm{mM}(*)$ and $100 \mathrm{mM}(\mathbf{\square})$. (b) Conductivity of 60 and $120 \mathrm{~nm}$ thick films measured in dry and wet air. The circle and triangle indicate the plots of 60 and $120 \mathrm{~nm}$ thick films, respectively, and white and dark mean the wet and dry atmosphere, respectively.

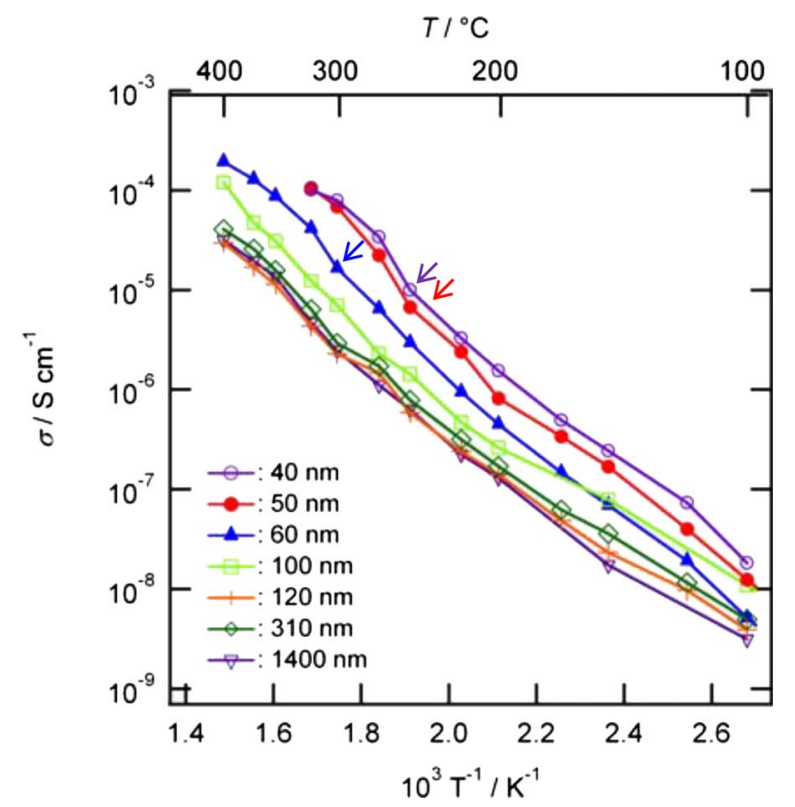

Figure 4. (Color online) Arrhenius plots of proton conductivity of $\mathrm{Al}_{x} \mathrm{Si}_{1-x} \mathrm{O}_{n}$ nanofilms with different thicknesses. The conductivity was measured in nonhumidified, dry atmosphere. The arrows show the onset temperature of conductivity transition $\left(T_{\mathrm{c}}\right)$ in 40,50 , and $60 \mathrm{~nm}$ thick films.

water, if any, at all the thicknesses. This conductivity must be based on the migration of protons on thermally stable Brønsted acid sites, ${ }^{5,9}$ as further discussed below.

Proton conductivity of $\mathrm{Al}_{x} \mathrm{Si}_{1-x} \mathrm{O}_{n}$ films with varied thicknesses is given in Fig. 4. All the films show drastic increases of $\sigma$ by 4 orders of magnitude with increasing temperatures from 100 to $400^{\circ} \mathrm{C}$. The films with thicknesses of 40 and $50 \mathrm{~nm}$ reveal small resistance at elevated temperatures, so that their conductivity above $350^{\circ} \mathrm{C}$ could not be determined by our measurement setup. Surprisingly, the conductivity itself, even after correction for film thickness, is enhanced by reduction of film thickness at less than $100 \mathrm{~nm}$. The temperature dependence of the conduction is rather complex, and it does not obey a simple Arrhenius-type feature in all cases. With films of more than $120 \mathrm{~nm}$ thickness, the conductivity linearly increases with a slope of activation energy $E_{\mathrm{a}}$ of $0.5 \mathrm{eV}$ below $200^{\circ} \mathrm{C}$, with a break at around $200^{\circ} \mathrm{C}$, and tends to increase with a slope of $E_{\mathrm{a}}$ of $0.8 \mathrm{eV}$ above $200^{\circ} \mathrm{C}$. In films more than $120 \mathrm{~nm}$ thick, the conductivity is not dependent on the thickness. The conductivity with small $E_{\text {a }}$ below $200^{\circ} \mathrm{C}$ may be related to the presence of the residual (adsorbed) water even under nonhumidified air. The conductivity of sub-100 nm thick films linearly increases with a slope of $0.7 \mathrm{eV}$ in the lower-temperature region, jumps at around $250-300^{\circ} \mathrm{C}$, and gradually increases with a relatively small $E_{\mathrm{a}}$ of $\sim 0.5 \mathrm{eV}$ above the onset temperature of the jumping, $T_{\mathrm{c}}$. The $T_{\mathrm{c}}$ is lowered with decreasing film thickness, and the $T_{\mathrm{c}}$ values for the 40,50 , and $60 \mathrm{~nm}$ thick film are 250,250 , and $300^{\circ} \mathrm{C}$, respectively.

Figure 5 shows logarithmic plots of $\sigma$ of $\mathrm{Al}_{x} \mathrm{Si}_{1-x} \mathrm{O}_{n}$ films at $250^{\circ} \mathrm{C}$ against film thickness $d$. $\sigma$ is almost constant when $d$ is greater than $120 \mathrm{~nm}$, but it is markedly enhanced by reducing $d$ in the thickness range less than $120 \mathrm{~nm}$. The increase in $\sigma$ follows a power law with an index of -2.1 . It reaches the order of $10^{-5} \mathrm{~S} \mathrm{~cm}^{-1}$ at $40 \mathrm{~nm}$, and this value is greater than that of a $120 \mathrm{~nm}$ thick film by almost 20 -fold.

Enhanced ionic conductivity of nanostructured materials has been reported to arise from the formation of a space-charge region and is called the nanoionics effect. ${ }^{10}$ Guo et al. reported that the multilayer films made of stacks of an epitaxial $\mathrm{CaF}_{2} / \mathrm{BaF}_{2}$ bilayer showed increments of $\mathrm{F}^{-}$ion conductivity perpendicular to inter- 


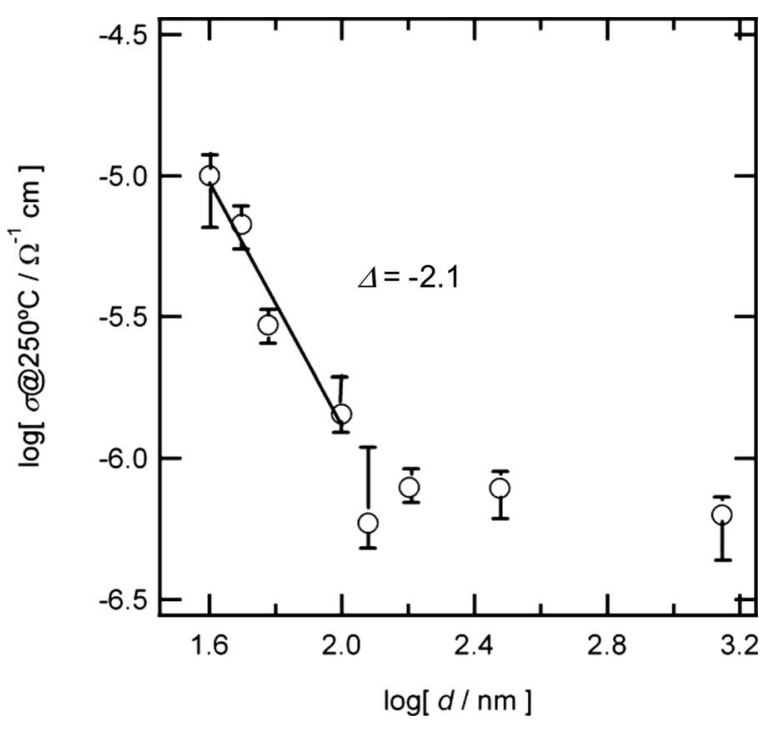

Figure 5. Log-log plot of conductivity $\sigma$ at $250^{\circ} \mathrm{C}$ vs thickness $d$.

faces as the thickness of the individual bilayer was reduced from 200 to $12 \mathrm{~nm}$, in spite of the constant total film thickness of $400 \mathrm{~nm} .^{7}$ Our films are prepared by the successive deposition of ultrathin layers $2-5 \mathrm{~nm}$ in thickness, and the different thickness of the individual layers arising from different concentrations (40 vs $100 \mathrm{mM}$ ) of the precursor sol does not cause a change in conductivity. Furthermore, we found that $\sigma$ of $50 \mathrm{~nm}$ thick films in dry air with $\mathrm{Au} / \mathrm{film} / \mathrm{ITO}$ and $\mathrm{Pt} / \mathrm{film} / \mathrm{Pt}$ configurations was the same as that of the Pt/film/ITO configuration. This suggests that the space-charge effect at the film/electrode interfacial region, if any, is not significant in the conductivity enhancement in our thin films.

Recently, Berkemeier et al. reported the thickness-dependence of $\mathrm{Li}^{+}$-ion conductivity in $0.2 \mathrm{Li}_{2} \mathrm{O} \cdot 0.8 \mathrm{~B}_{2} \mathrm{O}_{3}$ glass film. ${ }^{11,12}$ The conductivity of the glass film was exponentially enhanced by reduction of its thickness to less than $100 \mathrm{~nm}$, and this phenomenon was explained by the finite size effect in percolative conduction. ${ }^{12}$ The diffusion process of $\mathrm{Li}^{+}$ions in $\mathrm{Li}-\mathrm{B}-\mathrm{O}$ glass is mostly carried out by the nonbridged oxygen (NBO) site. The NBO sites tend to form an assemblage, a so-called cluster, and percolate from one edge to the opposite so as to form a conduction pathway (ionic diffusion channel). ${ }^{13}$ If the population of NBO sites is in the vicinity of the percolation threshold $P_{\mathrm{c}}(24.5 \%$ for site percolation of cubic lattice $\left.{ }^{14}\right)$, NBO clusters of various sizes accumulate inside the glass layer. Here, the feature length of the largest cluster is defined as $\zeta$. When the thickness of film $d$ is reduced to the range of the length of the largest NBO clusters, $(\zeta)$ pathways connecting the two electrodes are formed in glass network, and the thin film with $d$ of smaller than $\zeta$ reveals the increment in conductivity. In thicker films, the length of the cluster is smaller than $d$, and the conductive clusters become insulated in a poorly conducting matrix, resulting in the reduction of the ion conductivity to a thickness-independent value.

The thickness-dependent conductivity observed for our $\mathrm{Al}_{x} \mathrm{Si}_{1-x} \mathrm{O}_{n}$ nanofilms is analogous to that of the percolative $\mathrm{Li}^{+}$-ion conduction in thin lithium-borate glass. The finite scaling model of percolative conductivity in a system with size $L$ is given by the following equation, when $L$ is smaller than $\zeta^{14}$

$$
\Sigma(L, \zeta) \propto(L / \zeta)^{-\tau} \approx L^{-\tau}
$$

Here, $\Sigma$ is the total conductivity of the system, $\tau$ is a critical index, and $L$ corresponds to $d$ in this study. Theoretically, the index $\tau$ is reported to be 2.3 for the site percolation in a three-dimensional system. ${ }^{14,15}$ The solid line of Fig. 5 is obtained by linear fitting for the data of less than $100 \mathrm{~nm}$ thickness. The slope is about $2.1 \pm 0.3$, and this value is close to the theoretical value of $\tau$. Therefore, we

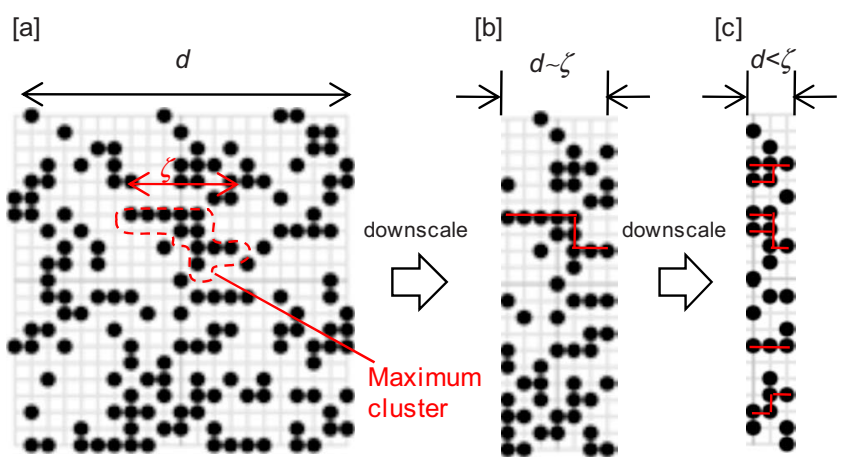

Figure 6. (Color online) 2D geometrical model of scaling of conductivity in $\mathrm{Al}_{x} \mathrm{Si}_{1-x} \mathrm{O}_{n}$ nanofilms. (a) Site percolation of black circles on a $20 \times 20$ square lattice with occupation probability of 0.35 . This probability is less than the theoretical percolation threshold $P_{\mathrm{c}}(0.5)$, so that the size of clusters of black circles is smaller than the lattice length $d$. (b) With downscaling, $d$ is in the range of the feature length of maximum cluster $\zeta$, and the black circles percolate from one edge to the opposite. (c) The smaller clusters also percolate with smaller $d$, and thus the number of percolation clusters is increased.

may assume that the enhancement of proton conductivity at $d$ $<100 \mathrm{~nm}$ is caused by the finite-size scaling effect of the percolative conduction system.

The percolative conduction behavior indicates that the $\mathrm{Al}_{x} \mathrm{Si}_{1-x} \mathrm{O}_{n}$ nanofilm has a heterogeneous structure composed of conductive moiety (it is like an $\mathrm{NBO}$ site in $\mathrm{Li}^{+}$-conducting $\mathrm{Li}-\mathrm{P}-\mathrm{O}$ glass) and poor-conducting matrix. The former may consist of the active acid sites, although the precise structure is unclear yet. Figure 6 is the two-dimensional (2D) representation of the geometrical model for percolation conductivity in $\mathrm{Al}_{x} \mathrm{Si}_{1-x} \mathrm{O}_{n}$. It shows the site percolation on a square lattice, where black circles randomly occupy the site of the lattice with a constant probability $(0.35)$ less than that of theoretical $P_{\mathrm{c}}(0.5) .{ }^{14}$ Here, the glass network of aluminosilicate and the active acid site on network are approximated by a square lattice and black dots, respectively, and it is assumed that the proton can only migrate between the black circle on the nearest-neighbor sites; thus, the assemblage of the nearest-neighbor circles, the cluster, behaves as a protonic conduction channel. When the film thickness $d$ is larger than $120 \mathrm{~nm}$, it is longer than $\zeta$, so that clusters connecting both electrodes are not formed and the film remains in the low (normal) conductive phase (Fig. 6a). Scaling of conductivity of our $\mathrm{Al}_{x} \mathrm{Si}_{1-x} \mathrm{O}_{n}$ film starts at $d$ of $100 \mathrm{~nm}$, suggesting that $\zeta$ in the film is about $100 \mathrm{~nm}$ in our $\mathrm{Al}_{x} \mathrm{Si}_{1-x} \mathrm{O}_{n}$ film. Hence, the active acid site is percolated between both electrodes at this thickness (Fig. 6b). In $d<100 \mathrm{~nm}(\zeta)$, more conductive clusters percolate with decreasing $d$ (Fig. 6c) by following Eq. 1. The conductivity becomes the maximum when $d$ is the same as the unit size of a conductive domain (corresponding to the lattice constant of the square lattice in Fig. 6c).

The conduction characteristics of the $\mathrm{Al}_{x} \mathrm{Si}_{1-x} \mathrm{O}_{n}$ film appear more complex at a thickness below $100 \mathrm{~nm}$. In the case of aluminosilicate films, the adsorbed water may provide additional proton carriers by association of water and oxygen vacancy

$$
\mathrm{V}_{\mathrm{O}}^{\cdot}+\mathrm{H}_{2} \mathrm{O} \leftrightarrows 2 \mathrm{H}_{i}+\mathrm{O}_{\mathrm{O}}^{\times}
$$

The conductivity, $\sigma$, of thicker films is more sensitive to the adsorbed water than that of the sub-100 nm thick film. This is curious, as protons given by Eq. 2 should diffuse from the surface into the film interior more efficiently with thinner films. On the basis of Eq. 2 , the incorporation of protons in the interior of films is strongly related to the concentration and diffusion of oxygen vacancy. Therefore, this anomaly may be explained by assuming that the concentration of oxygen vacancy in the interior of thinner films is much lower than that of the thicker films, and thus additional protons do 
not accumulate in the thin films $(<100 \mathrm{~nm})$ in the wet atmosphere. The apparent jump of $\sigma$ was observed for the sub- $100 \mathrm{~nm}$ thick films at temperatures above $250^{\circ} \mathrm{C}$, indicating the presence of an additional thermal activation process in thin films. This can be explained by the formation of the new percolative conduction cluster as a result of thermal activation of the protonic acid site. A more precise mechanism for the unique proton conductivity of $\mathrm{Al}_{x} \mathrm{Si}_{1-x} \mathrm{O}_{n}$ thin films will be reported after our additional experiments.

In summary, it is demonstrated that the proton conductivity of amorphous aluminosilicate nanofilms is much enhanced by reducing the film thickness to the sub-100 $\mathrm{nm}$ regime. This unique feature is explicable by the existence of the percolative proton conduction, which gives rise to the marked increase of conductivity due to the size scaling in the percolative cluster. As a result, the intrinsic conductivity, $\sigma$, for the $40 \mathrm{~nm}$ thick film $\left(1 \times 10^{-5} \Omega \mathrm{cm}^{2}\right)$ is larger than that of the corresponding thick $(120 \mathrm{~nm}$ ) film (on the order of $10^{-7} \Omega \mathrm{cm}^{2}$ ) by 20 -fold at $250^{\circ} \mathrm{C}$. Thus, the ASR value, which is an important element in determining fuel cell efficiency, is enhanced by reduction of film thickness as well as by the accompanying formation of percolative conduction cluster, in the sub- $100 \mathrm{~nm}$ region. This conclusion may apply to inorganic thin films other than aluminosilicate. The current finding should be extremely useful for the development of high-efficiency proton conductors.
Hokkaido University assisted in meeting the publication costs of this article.

\section{References}

1. J. H. Shim, C.-C. Chao, H. Huang, and F. B. Prinz, Chem. Mater, 19, 3850 (2007) 2. H. Huang, M. Nakamura, P. Su, R. Fasching, Y. Saito, and F. B. Prinz, J. Electro chem. Soc., 154, B20 (2007).

3. N. Ito, M. Iijima, K. Kimura, and S. Iguchi, J. Power Sources, 152, 200 (2005).

4. Y. Aoki, E Muto, S. Onoue, A. Nakao, and T. Kunitake, Chem Commun (Cambridge), 2007, 2396

5. Y. Aoki, E. Muto, A. Nakao, and T. Kunitake, Adv. Mater. (Weinheim, Ger.), Accepted.

6. S. Azad, O. A. Marina, C. M. Wang, L. Saraf, V. Shutthanandan, D. E. McCready, A. El-Azab, J. E. Jaffe, M. H. Engelhard, C. H. F. Peden, et al., Appl. Phys. Lett., 86, 131906 (2005)

7. X. X. Guo, I. Matei, J.-S. Lee, and J. Maier, Appl. Phys. Lett., 91, 103102 (2007) 8. J. T. S. Irvine, D. C. Sinclair, and A. R. West, Adv. Mater. (Weinheim, Ger.), 2, 132 (1990).

9. C. E. Bronnimann, I.-S. Chuang, B. L. Hawkins, and G. E. Marciel, J. Am. Chem Soc., 109, 1562 (1987).

10. J. Maier, Nat. Mater, 4, 805 (2005)

11. F. Berkemeier, M. R. S. Abouzari, and G. Schmitz, Appl. Phys. Lett., 90, 113110 (2007)

12. F. Berkemeier, M. R. S. Abouzari, and G. Schmitz, Phys. Rev. B, 76, 024205 (2007).

13. A. Vegiri and C. E. Varsami, J. Chem. Phys., 120, 7689 (2004).

14. D. Stauffer and A. Aharony, Introduction to Percolation Theory, p. 92, CRC Press, Boca Raton, FL (1991).

15. N. Jan, Physica A, 266, 72 (1999). 